\title{
Constructing halitosis sensor for early detection in periodontal diseases
}

\author{
Nurlindah Hamrun, Filzah Azalia, ${ }^{*}$ Nurul Auliya, Muhammad Riswan
}

\section{Abstract}

Objective: The purpose of this research is to create a halitosis sensor device that can detect periodontal disease through bad breath.

Material and Methods: The method used is MQ 136 gas sensor which possesses high sensitivity to $\mathrm{H} 2 \mathrm{~S}$ gas and can monitor organic vapor including sulfur well.

Results: The result of the resistance value obtained in the sensor is changed to the concentration value of the substance and displayed in the LCD. When the power button is switched on then the power supply from the battery is flowing in the Arduino and LCD. When the "result" button is pressed it will appear the desired result on the LCD in the form of H2S element concentration and also predicted the status of periodontal disease suffered by the patient.

Conclusion: This halitosis sensor can detect early periodontal disease experienced by a person so that patients with a suspected periodontal disease can be treated as soon as possible.
Department of Oral Biology, Faculty of Dentistry, Hasanuddin University, Makassar, Indonesia
*Correspondence to: Filzah Azalia, Department of Oral Biology, Faculty of Dentistry, Hasanuddin University, Makassar, Indonesia filzahazalia@gmail.com

Received: 1 March 2020

Revised: 26 April 2020

Accepted: 19 July 2020

Available Online: 1 August 2020

Keyword: Halitosis sensor, Hydrogen Sulfide, Periodontal

Cite this Article: Hamrun N, Azalia F, Auliya N, Riswan M. 2020. Constructing halitosis sensor for early detection in periodontal diseases. Journal of Dentomaxillofacial Science 5(2): 110-113. D0I: 10.15562/jdmfs.v5i2.1080

\section{Introduction}

Periodontal disease is a common dental and oral health problem in Indonesia with a prevalence of 96.58 percent in all age groups. ${ }^{1}$ Periodontal disease is an inflammatory process caused by bacteria that affect the periodontium tissue and if not treated promptly will cause the tooth to release itself from the gums. Generally, periodontal disease is chronic so that complaints or symptoms that arise only realized by the sufferer if the situation is advanced. Periodontal disease can be detected early by knowing the degree of halitosis a person.

Halitosis or bad breath is a general term used to describe an odor or odor that is not preferred when blown air, regardless of whether the substance odor originated from oral or derived from non-oral. In the oral cavity of a person, there are exogenous protein substrates (food waste) and endogenous proteins (desquamation of the mouth epithelium, salivary and blood proteins) containing many sulfur-containing amino acids (S). There are also gram-positive and gram-negative microorganisms, which are commonly found in oral epithelial cells with desquamation, dental plaque, and dorsal tongue. $^{2}$

The result of halitosis is the release of volatile sulfur compounds (VSCs) through anaerobic Gram-negative bacterial spoilage activity. ${ }^{3}$ The process of occurrence of VSCs is preceded by breaking of protein substrates from food waste by gram-negative bacteria that are proteolytic into peptide chains and amino acids such as methionine, cysteine, and cystine. The amino acids will be reduced to methyl mercaptan, hydrogen sulfide and dimethyl sulfide. ${ }^{2}$ It has been reported that the main substance of physiological halitosis is H2S. ${ }^{4}$

One way to measure halitosis is to use a gas sensor. Gas sensors are devices that can generate electrical signals as their interaction functions with gaseous or organic compounds. This sensor can change the conductivity to explain the gas concentration signal through a simple circuit. The MQ 136 gas sensor possesses high sensitivity to $\mathrm{H} 2 \mathrm{~S}$ gas and can monitor organic vapors including sulfur well. ${ }^{5}$

\section{Material and Methods}

The manufacture and testing of the equipment is done in the Laboratory of Instrumentation and Control System of Gowa Engineering Faculty and is conducted for five months. A literature study is done by studying textbooks and various references in other journals that support the design of halitosis sensors and consult with several professors in their field.

Some tools are purchased at a hardware store in Makassar and some are also purchased through the Online Shop. The tools and materials needed to realize this idea are solder, lead, rainbow cable, Li-ion 18560 battery, resistor, LED, LCD $8 \times 2$, Dupont housing female, Dupont housing male, push button, on-off button, MQ136 sensor, Arduino pro mini, step-up module boost, digital multimeter, and cover made using 3D print. 
$\mathrm{H} 2 \mathrm{~S}$ and $\mathrm{CH} 3 \mathrm{SH}$ on VSCs almost $90 \%$ produce odor, while $\mathrm{CH} 3 \mathrm{SCH} 3$ is only about $10 \%$. Thus, halitosis checking can be known from the dominant element of hydrogen sulfide. The hydrogen sulfide element present in air respiration can be determined by using gas sensors that are sensitive to the gas. ${ }^{6}$ The gas sensor is a device capable of generating electrical signals as their interaction function with chemical compounds, in which case gas or vapor of organic compounds. Example the MQ136 sensor is a gas sensor that is sensitive to $\mathrm{H} 2 \mathrm{~S}$ gas. Sensitive material to this sensor is $\mathrm{SnO} 2$ that has a lower conductivity in water when there is $\mathrm{H} 2 \mathrm{~S}$ gas the sensor conductivity will increase along with the gas concentration also increased. The user of this sensor can change the conductivity to explain the gas concentration signal through a simple circuit. This MQ 136 gas sensor possesses high sensitivity to $\mathrm{H} 2 \mathrm{~S}$ gas and can monitor organic vapor including sulfur well. ${ }^{5}$

Figure 1 at the stage of instrumentation, the components are assembled like the above instruments. It uses sensors that detect $\mathrm{H} 2 \mathrm{~S}$ levels in the mouth. The result of the resistance value obtained in the sensor is changed to the concentration value of the substance and displayed in the LCD. From the concentration value obtained, then through the classification stage then we can suspect periodontal disease that occurs in a person. When the power button is activated when the power supply from the battery flows currently on the Arduino and LCD. When the "check" button is pressed then the condition of the sensor in the active state and perform calibration for a while until the sensor is ready and when the air input valve is opened then the sensor will detect the gas concentration in the small space that is in the tool. When the "result" button is pressed it will appear the desired results on the LCD in the form of $\mathrm{H} 2 \mathrm{~S}$ element concentration and also the prediction of oral disease suffered.

The process of making halitosis sensor with the stages as follows; It starts with the testing of each module and component to make sure the modules and components work properly. After that assemble the components and modules in the breadboard to test the sensor readings and the microcontroller. After all, is ensured fine, the next microcontroller in the program with Arduino IDE application to process the data according to who want to show. After the programming stage, then on the raft of

\begin{tabular}{|c|c|c|}
\hline Concentration of $\mathrm{H}_{2} \mathrm{~S}$ & $\mathrm{H}_{2} \mathrm{~S}$ Sensor & Arduino \\
& LCD Output & $\begin{array}{c}\text { Value Of } \\
\text { Concentration }\end{array}$ \\
\hline
\end{tabular}

the power supply circuit on the tool by checking the voltage and output current of the step-up module. Then connect the tool with its power supply. After all, has been achieved than in the tool raft in such a way on the design of tools that have been made. Then provide insulation on the connection of the still-open cable and ensure the halitosis sensor still running properly.

The tool function testing phase is performed after the halitosis sensor has been completed. This function test is performed to determine the success rate of halitosis sensor in detecting Hydrogen Sulfide gas (H2S) in halitosis.

\section{Results}

Solder and lead are used for connecting circuits, jumper cables are used to connect components to one another so that between microcontrollers and sensors can be connected, Li-Ion Battery 18650 is used as the main power supply of halitosis sensors, resistors are used to inhibit current, LEDs
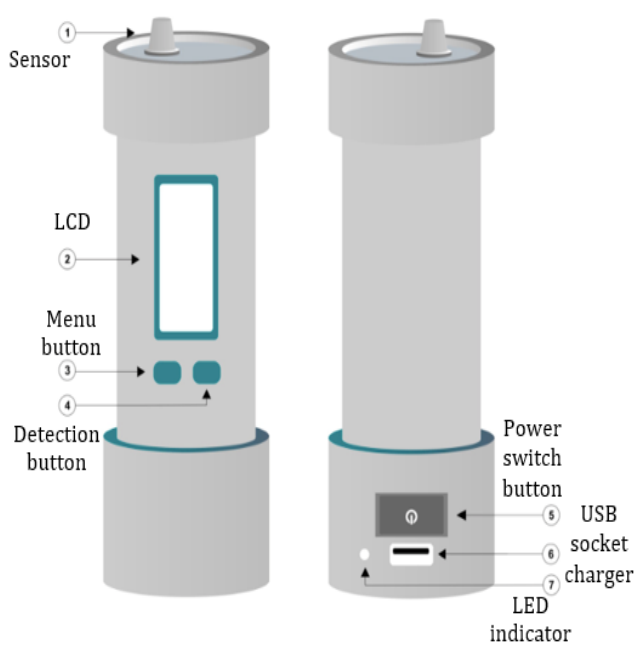

Figure 2 Design of halitosis sensor

\begin{tabular}{|c|c|}
\hline Category & Description \\
\hline $0:$ Absence of odour & Odour cannot be detected \\
\hline 1: Questionable odour & $\begin{array}{l}\text { Odour is detectable, although the } \\
\text { examiner could not recognize it as } \\
\text { malodour }\end{array}$ \\
\hline 2: Slight malodour & $\begin{array}{l}\text { Odour is deemed to exceed the } \\
\text { threshold of malodour recognition }\end{array}$ \\
\hline 3: Moderate malodour & Malodour is definitely detected \\
\hline 4: Strong malodour & $\begin{array}{l}\text { Strong malodour is detected, but } \\
\text { can be tolerated by examiner }\end{array}$ \\
\hline 5: Severe malodour & $\begin{array}{l}\text { Overwhelming malodour is } \\
\text { detected and cannot be tolerated by } \\
\text { examiner (examiner instinctively } \\
\text { averts the nose) }\end{array}$ \\
\hline
\end{tabular}

Figure 3 Organoleptic Score 


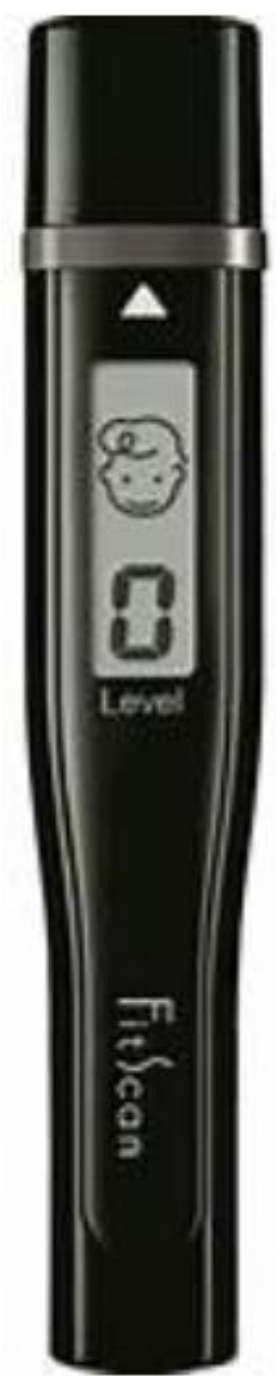

Figure 4 FitScan Breath Checker

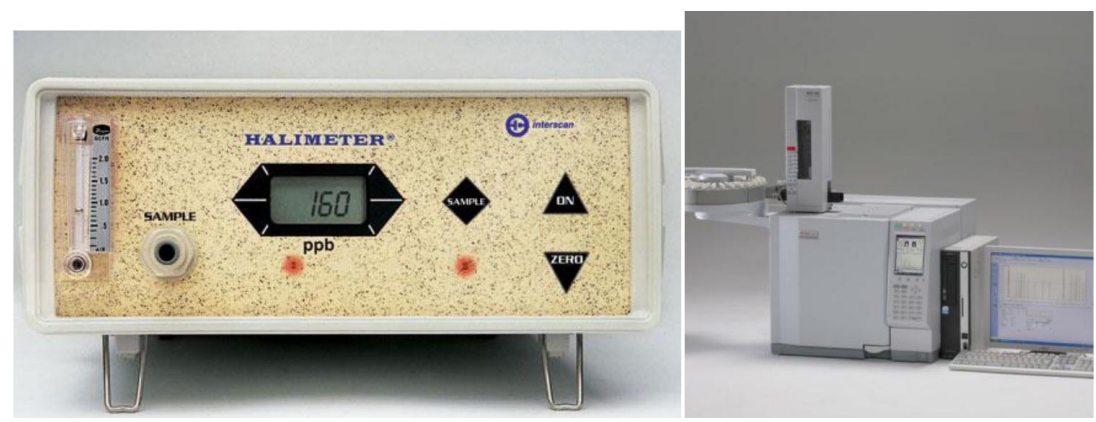

Figure 5 A. Halimeter, B. Gas Chromatography

are used as indicator, arduino pro mini is used as microcontroller used to process data, LCD eight segment row times two segment column is used to display the reading result from Arduino pro mini, Dupont female and male is used as cable head for cable connection is strong and safe, push button is used as input to set the display and command on the microcontroller, on of button is used as circuit breaker and connector of device from power supply, sensor MQ 136 is used as module to detect H2S content, step up boost module is used to raise voltage from battery previously 4.2 volts become constant 5 volts, as well as a digital multimeter used to measure voltage, resistance, and current. This tool is designed to resemble a drink bottle to make it easier for users to hold the tool figure 2.

Organoleptic score is done by assessing the breath of a person doing a breath evaluation using nose smell figure 3 .

Figure 4 FitScan Breath Checker (HC-212SF, Tanita Corporation, USA) can measure the content of volatile sulfur compounds (VSCs), hydrogen sulphide (H2S), methyl mercaptan (CH3SH), dimethyl sulphide (CH3-S-CH3), and hydrocarbons in the oral cavity, taking readings in 5 levels: 0 - no odor, 1 - slight odor, 2 - moderate odor, 3 heavy odor, 4 - strong odor, 5 - intense odor

Figure $5 \mathrm{~A}$ the portable sulfide monitor (Halimeter, Model RH-17K; Interscan Co., Chatsworth, CA, USA) has high sensitivity for VSCs.

Chromatography is using gas to identify compounds found in a sample figure 5B.

\section{Discussion}

Halitosis sensor serves to detect the level of halitosis on a person's breath by measuring the levels of VSC contained in bad breath. In addition to this halitosis sensor there are also several ways to detect halitosis levels such as using an Organoleptic Score, Breath Checker, Halimeter, and Gas Chromatography.

Organoleptic score is done by assessing the breath of a person doing a breath evaluation using nose smell as a means to make research. This check is easy and inexpensive, because it does not require special tools. The nose can detect up to ten thousands different odors. The drawback is that this technique is not really objective. In addition other factors outside the smell of breath can affect organoleptic evaluation.?

How to use this breath checker is after switching on the breath checker, the clinician waited a countdown of 5 seconds to clean the sensor until device was ready for use. The patient then breathed into the designated openings at $1 \mathrm{~cm}$ away from the mouth until it beeped. ${ }^{8}$

Patients were asked to breathe through the nose, with the mouth closed, for 1 minute. A straw attached to the Halimeter was then inserted into the mouth and air was withdrawn from the mouth for analysis. The results of VSC levels in breath air were recorded as parts per billion (ppb) of sulfide equivalents. Concentrations were determinded in triplicate and a mean value was calculated. Measurements of VSCs was usually performed in the morning in fasting condition to avoid the 
influence from ingested foods. ${ }^{9}$ Halimeter cannot specifically test types of VSCs. Halimeter produces a less definitive measurement of someone's breath. ${ }^{7}$

Gas chromatography is used by dentists for halitosis studies and can quantify the exact level of various compounds present in a person's breath. This gas chromatography is considered the gold standard or the best way to measure halitosis. But it has not been widely used in research, because it is relatively expensive, to operate it requires special training, and requires a lot of time in every breath measurement.

The difference that this halitosis sensor has with other bad breath detectors is how to use it. How to use halitosis sensors is easier than other tools that look more difficult. To use halitosis sensors we only need to press the "check" button then exhale the sensor and press the "result" button to see the results obtained between 3 levels, namely Normal, Halitosis without periodontal disease, or suspect periodontal disease. Then, this tool also when compared with the organoleptic test results obtained are more objective and accurate. In addition, when compared with other tools such as Halimeter or Gas Chromatography the price is more affordable because the tools and materials used are cheaper. And the main thing, among all the bad breath detectors, none can detect early periodontal disease other than this halitosis sensor.

\section{Conclusion}

This halitosis sensor has a portable shape, easy in taking data, and accurate in detecting the presence of VSC elements in a person's bad breath. This halitosis sensor can also detect early periodontal disease experienced by a person so that patients with a suspected periodontal disease can be treated as soon as possible.

\section{Acknowledgment}

The author would like thank the advisor and everyone who have been support the author to do this research.

\section{Conflict of Interest}

The authors report no conflict of interest.

\section{References}

1. Wijaksana IKE. Infectobesity and periodontitis: a twoway relationship between obesity and periodontal disease. ODONTO Dent J 2016;3: 67. (In Indonesia)

2. Widagdo Y, Suntya K. Volatile sulfur compounds sebagai penyebab halitosis. Interdental 2012;5: 1-2.

3. Alshehri FA. Knowledge and attitude of Saudi individuals toward self-perceived halitosis. Saudi J Dent Res 2016;7: 91-95.

4. Kuroshita R. Relation between counts of periodontophatic bacteria in the tongue coat of healthy subject and the concentration of volatile sulfur compounds un their breath. Pediatric Dent J 2010;20: 57-60.

5. Kapoor U, Sharma G, Juneja M, et al. Halitosis: current concepts on etiology, diagnosis and management. Eur J Dent 2016;10: 292-300.

6. Sembiring IA, Adam AM. Periodontal management of the elderly with medical compromise: a case report. J Dentomaxillofac Sci 2019;4: 59-62.

7. Senjaya AA. Perawatan halitosis. Jurnal Skala Husada 2011;8: 128-129.

8. Nogalcheva AN, Konstantinova D. Halitosis in patients with end-stage chronic kidney disease undergoing chronic dialysis treatment. Int J Sci Res 2016;5: 875.

9. Kim JG. Halimeter ppb levels as the predictor of erosive gastroesophageal reflux disease. Gut and Liver 2010;4: 321.

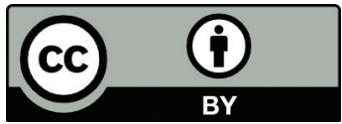

This work is licensed under a Creative Commons Attribution 